\title{
Methods for improving the sensitivity and specificity of the fibrin plate
}

\author{
NEIL EDWARD \\ From the Department of Medicine, University of Aberdeen, Foresterhill, Aberdeen
}

SYNOPSIS Fibrinogen prepared by the method of Blombäck and Blombäck is most suitable with respect to sensitivity and stability for the estimation of urokinase by the fibrin plate technique. Adding plasminogen to a concentration of around 0.5 casein units $/ \mathrm{ml} 0.2 \mathrm{~g} \%$ clottable fibrinogen provides substrate conditions of optimal sensitivity and reproducibility.

The fibrin plate is widely used in studies of the fibrinolytic enzyme system in the measurement of plasminogen activator and plasmin. It was first described by Permin (1947) and later Astrup and Müllertz suggested optimal conditions for its use in the estimation of plasmin (Astrup and Müllertz, 1952). It is particularly useful for the estimation of the plasminogen activator present in urine, urokinase (Bjerrehuus, 1952; Smyrniotis, Fletcher, Alkjaersig, and Sherry, 1959; Holemans, McConnell, and Johnston, 1966). Modifications have since been described in an attempt to improve the accuracy and reproducibility. Very little attention, however, has been paid to the plasminogen content of the fibrinogen preparation used. This report demonstrates the importance of the plasminogen concentration in reproducibility of results and that for this purpose the plasminogen content of the fibrin plate must be kept constant.

\section{Material and Methods}

\section{BUFFER}

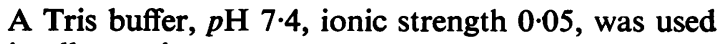
in all experiments.

\section{UROKINASE}

Obtained from Leo Laboratories Ltd and dissolved in buffer to the required concentration, expressed in Ploug units/ml (Ploug and Kjeldgaard, 1957).

\section{PLASMINOGEN}

Obtained from Kabi Pharmaceuticals Ltd and the results of assays are expressed in casein units (Alkjaersig, Fletcher, and Sherry, 1959).

Received for publication 30 September 1971.
BOVINE PLASMA FIBRINOGEN

This was prepared by three methods: (1) Ammonium sulphate precipitation (McFarlane, 1965); (2) Jaques phosphate buffer (Jaques, 1943); and (3) cold ethanol glycine precipitation (Blombäck and Blombäck, 1956).

For the preparation of the fibrin plates solutions containing $0.2 \mathrm{~g}$ clottable protein per $100 \mathrm{ml}$ were used.

\section{THROMBIN}

Obtained from Parke Davis Co Ltd, this was used in a concentration of $67 \mathrm{NIH}$ units $/ \mathrm{ml}$.

\section{FIBRIN PLATE}

Twenty-five $\mathrm{ml}$ fibrinogen solution was clotted in a Plexiglas dish $11.5 \mathrm{~cm}$ diameter by the addition of $50 \mathrm{NIH}$ units of thrombin in $0.75 \mathrm{ml}$ buffer. The plates were allowed to stand at room temperature for at least $30 \mathrm{~min}$ before being used. Thirty $\mu 1$ volumes of the test sample were applied in triplicate to the plates which were then incubated for 18 hours at $37^{\circ} \mathrm{C}$. The product of two perpendicular diameters of the zone of lysis was taken as the measure of fibrinolytic activity.

URINE

Aliquots of 24-hour specimens collected in $5 \mathrm{ml}$ thymol-isopropanol preservative were used. During collection the urine was stored at room temperature. Tests were carried out within two hours of completion of the collection period.

\section{Results}

Table I illustrates the wide variation in sensitivity of 


\begin{tabular}{ll}
\hline Method of Fibrinogen Preparation & Area of Lysis $\left(\mathrm{mm}^{2}\right)$ \\
\hline $\mathrm{NH}_{\mathrm{C}_{2} \mathrm{SO}_{4} \text { precipitation }}$ & 289 \\
Jaques phosphate buffer & 150 \\
Blombäck and Blombäck & 358
\end{tabular}

Table I Areas of lysis on fibrin plates produced by $30 \mu l$ of 8 units/ml urokinase

different fibrinogen preparations to a standard quantity of activator (urokinase). Each value represents the mean of four estimations. The fibrinogens were all prepared from the same sample of bovine plasma. Table II shows the small variation in sensitivity of different fibrinogen preparations made by the same method (Blombäck and Blombäck, 1957) but from batches of bovine plasma obtained from different animals. These differences are not significant.

\begin{tabular}{ll}
\hline Preparation & Area of Lysis $\left(\mathrm{mm}^{2}\right)$ \\
\hline B.B. 1 & 358 \\
B.B. 2 & 326 \\
B.B. 3 & 375 \\
B.B. 4 & 340 \\
\hline
\end{tabular}

Table II Areas of lysis on fibrin plates produced by $30 \mu$ l of 8 units/ml urokinase ${ }^{1}$

${ }^{1}$ Four different fibrinogens prepared by the method of Blombäck and Blombäck were used.

When plasminogen was added to a preparation of 1-4 fibrinogen (Blombäck and Blombäck, 1956) to give final concentrations of $1,5,10,15,20,25$, and 30 casein units per plate increasing areas of lysis were obtained until at 30 units/plate the complete layer of fibrin had lysed before the end of the incubation period. The results are illustrated in Figure 1. At 20 and 25 casein units per plate small areas of lysis were produced in parts separate from the zones of lysis produced by urokinase. The plates containing up to 15 units of plasminogen remained stable after 12 hours' storage at room temperature or 24 hours at $4^{\circ} \mathrm{C}$. The plateau part of the curve from 5 to 15 units per plate gave the best combination of sensitivity and stability.

When dilutions of urine and urokinase were compared on plates of different plasminogen content parallel dilution curves were only obtained when the plasminogen content was around 10 units per plate. Figure 2 illustrates this change in slope of dilution curves. The results for urine and standard urokinase are qualitatively similar but differ markedly in degree; with increasing plasminogen content of the fibrin plate the value for ' $a$ ', denoting the slope of the dilution curve, falls from 0.58 to 0.39 for purified

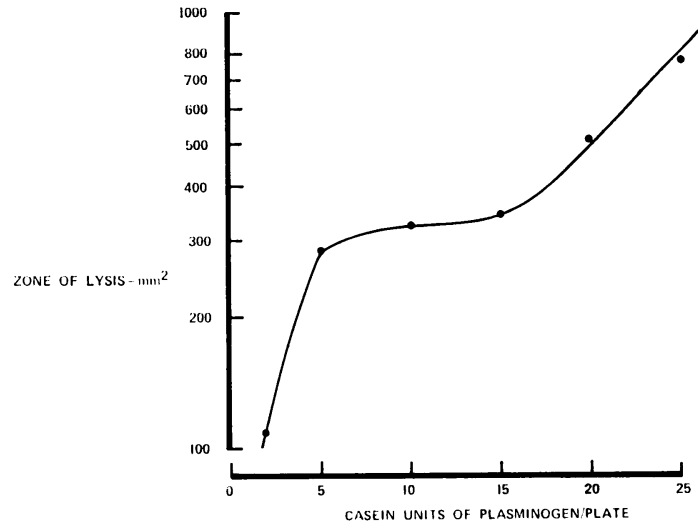

Fig. 1 Effect of increasing the plasminogen content of fibrin plates. Lysis produced by $30 \mu l$ standard urokinase 4 units per $\mathrm{ml}$.

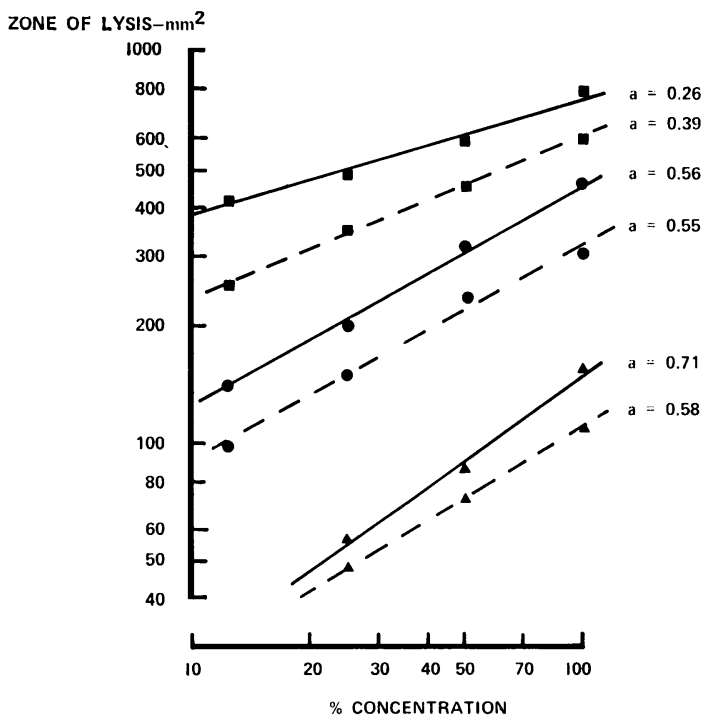

Fig. 2 Effect of change in plasminogen content of fibrin plates on serial dilutions of standard urokinase (- - - ) $100 \%$ equivalent to 8 units per $\mathrm{ml}$, and normal urine ( - ). ' $a$ ' denotes slope of line. $\Delta-\Delta, 0 \cdot 2$ units plasminogen per $\mathrm{ml}$ fibrinogen; - 0.4 units plasminogen per ml fibrinogen; 0.6 units plasminogen per ml fibrinogen. 
urokinase and from 0.71 to $\mathbf{0 . 2 6}$ for normal urine. It is concluded that for comparative purposes the plasminogen content of the fibrinogen used in the preparation of fibrin plates should be between 0.2 and 0.6 casein units per $\mathrm{ml}$.

\section{Discussion}

These results demonstrate the wide variation in sensitivity of different preparations of fibrinogen converted to fibrin to a standard amount of plasminogen activator. This may be due to the presence of anti-activator or anti-plasmin in the fibrin layer, to deficient content of plasminogen or to denaturation of the fibrinogen during preparation rendering it less sensitive to the action of plasmin. The latter possibility is unlikely, as McFarlane (1965) has shown that ammonium-sulphate-precipitated fibrinogen behaves in vivo in an identical manner to native fibrinogen indicating that no denaturation has taken place whereas exposure to low temperature and alcohol, as happens in the Blombäck and Blombäck method, results in significant denaturation.

Variation in plasminogen content of the fibrin layer has a major effect on the sensitivity of the fibrin plate technique in measuring urinary and purified urokinase. The results presented also indicate that plasminogen content has a marked effect on the slope of dilution curves. Solutions of an enzyme which differ only in the concentration of that enzyme have a $\log -\log$ relationship: $\log A=a \log$ $c+b$, where $A$ is the area of lysis, $c$ the concentration of the enzyme, and $a$ is a constant denoting the slope of the curve. The value for a standard urokinase gradually rises with increasing plasminogen content of the fibrin plate. When urinary urokinase is measured the same phenomenon is seen but it is greater in magnitude. The values for ' $a$ ' for standard urokinase and urinary urokinase are closest when the concentration of plasminogen is approximately 0.5 units per $\mathrm{ml}$ fibrinogen. At this concentration interaction of the urokinase with residual inhibitors appears to be minimal.

I am grateful to the late Professor H. W. Fullerton and Dr M. MacLeod for encouragement and advice and also to Professor A. S. Douglas for helpful criticism of the text.

\section{References}

Alkjaersig, N., Fletcher, A. P., and Sherry, S. (1959). The mechanism of clot dissolution by plasmin. J. clin. Invest., 38, 1086-1095.

Astrup, T., and Müllertz, S. (1952). The fibrin plate method for estimating fibrinolytic activity. Arch. Biochem., 40, 346-351.

Bjerrehuus, I. (1952). Fibrinolytic activity of urine. Scand. J. clin. Lab. Invest., 4, 179-182.

Blombäck, B., and Blombäck, M. (1957). Purification of human and bovine fibrinogen. Arkh. Kemi., 10, 415-443.

Holemans, R., McConnell, D. and Johnston, J. G. (1966). Urokinase levels in urine after nicotinic acid injection. Thromb. Diathes. haemorrh. (Stuttg.), 15, 192-204.

Jaques, L. B. (1943). The reducing properties of fibrinogen. Biochem. J., 37, 344-349.

McFarlane, A. S. (1965). The preparation of $I^{131}$ and $I^{12 s}$ labelled plasma proteins. In Radioisotope Techniques in the Study of Protein Metabolism. (International Atomic Energy Agency Technical Report Series, no. 45, pp. 3-6.)

McFarlane, A. S., Todd, D., and Cromwell, S. (1964). Fibrinogen catabolism in humans. Clin. Sci., 26, 415-420.

Marsh, N. A., and Vere, D. W. (1967). A comparative account of standard and urinary urokinase. Clin. chim. Acta, 16, 389-396.

Permin, P. M. (1947). Properties of the fibrinokinase-fibrinolysin system. Nature (Lond.), 160, 571-572.

Ploug, J., and Kjeldgaard, N. O. (1957). Urokinase: an activator of plasminogen from human urine. I. Isolation and properties. Biochim. biophys. Acta (Amst.), 24, 278-282.

Smyrniotis, F. E., Fletcher, A. P., Alkjaersig, N., and Sherry, S. (1959). Urokinase excretion in health and its alteration in certain disease states. Thrombos. Diathes. haemorrh. (Stuttg.), 3, 257-270.

Walton, P. L. (1966). An improved fibrin plate method for the assay of plasminogen activators. Clin. chim. Acta, 13, 680-684. 